\title{
Review Article \\ The Dystrophin-Glycoprotein Complex in the Prevention of Muscle Damage
}

\author{
Jessica D. Gumerson ${ }^{1}$ and Daniel E. Michele ${ }^{1,2}$ \\ ${ }^{1}$ Department of Molecular \& Integrative Physiology, University of Michigan, Ann Arbor, MI 48109, USA \\ ${ }^{2}$ Department of Internal Medicine, University of Michigan, 7732C Medical Science II, 1301 E Catherine Street, Ann Arbor, \\ MI 48109-0622, USA
}

Correspondence should be addressed to Daniel E. Michele, dmichele@umich.edu

Received 13 May 2011; Accepted 3 July 2011

Academic Editor: Robert J. Bloch

Copyright (C) 2011 J. D. Gumerson and D. E. Michele. This is an open access article distributed under the Creative Commons Attribution License, which permits unrestricted use, distribution, and reproduction in any medium, provided the original work is properly cited.

\begin{abstract}
Muscular dystrophies are genetically diverse but share common phenotypic features of muscle weakness, degeneration, and progressive decline in muscle function. Previous work has focused on understanding how disruptions in the dystrophinglycoprotein complex result in muscular dystrophy, supporting a hypothesis that the muscle sarcolemma is fragile and susceptible to contraction-induced injury in multiple forms of dystrophy. Although benign in healthy muscle, contractions in dystrophic muscle may contribute to a higher degree of muscle damage which eventually overwhelms muscle regeneration capacity. While increased susceptibility of muscle to mechanical injury is thought to be an important contributor to disease pathology, it is becoming clear that not all DGC-associated diseases share this supposed hallmark feature. This paper outlines experimental support for a function of the DGC in preventing muscle damage and examines the evidence that supports novel functions for this complex in muscle that when impaired, may contribute to the pathogenesis of muscular dystrophy.
\end{abstract}

\section{Introduction}

Skeletal muscle is a dynamic tissue that routinely undergoes a significant degree of mechanical strain and cellular deformation with each contraction. In order to preserve normal skeletal muscle function throughout the lifetime of an individual, this complex tissue must be able to routinely undergo cell shortening and generate forces required for movement while at the same time limiting mechanical cellular injury and adapting to changing workloads. In muscular dystrophy, an imbalance between muscle damage or degeneration and muscle repair through stem-cell mediated regeneration is thought to contribute to the disease pathology and consequently results in a progressive decline in muscle function [1]. Mutations in a number of distinct genes can cause muscular dystrophy with varying degrees of severity, but precisely how each can negatively affect normal muscle function is unclear [2]. A significant number of muscular dystrophies result from mutations that affect the normal assembly of the dystrophin-glycoprotein complex at the sarcolemma in muscle. A longstanding hypothesis to explain the high degree of muscle damage and degeneration observed in dystrophic muscle is that mutations affect the function of critical structural proteins in muscle and in some way compromises the mechanical stability of the muscle fiber and/or its sarcolemma. This exacerbates the damage that occurs during normal muscle contractions and initiates a lethal cascade of events that can cause death of the myofiber [3-5]. In support of this, early studies demonstrated an increase in the number of necrotic fibers in muscles from muscular dystrophy patients that likely resulted from irreparable membrane damage as a consequence of normal muscle activity [6]. However, rather than dystrophic muscle suffering from an increased susceptibility to external damage, alternative hypotheses exist that could account for increased cell death. For example, that causative mutations may affect either the resting homeostasis of muscle cells or alter the ability of the muscle to adapt and repair following a normal "dose" of muscle injury. Although the importance of the dystrophin-glycoprotein complex in maintaining sarcolemma integrity is well supported, alternative functions 
for this complex have been proposed through the years and are now gaining significant experimental support $[7,8]$.

\section{The Dystrophin-Glycoprotein Complex}

The dystrophin-glycoprotein complex (DGC) is composed of several transmembrane and peripheral components and is highly expressed in the sarcolemma of skeletal muscle [9-11]. Mutations in genes that encode DGC components lead to the loss of either expression and/or function of the DGC in muscle. Dystroglycan is a protein central to this complex that spans the sarcolemma and binds to ligands in the surrounding basal lamina through $\alpha$-dystroglycan and to dystrophin inside the cell through $\beta$-dystroglycan [12]. Dystrophin in turn binds to the submembrane actin and intermediate filament cytoskeleton within fibers, thereby completing a link between the cytoskeleton and the extracellular matrix $[13,14]$. Costameres are concentrations of extracellular matrix receptor complexes that reside at the membrane in register with the Z-lines of sarcomeres within muscle fibers. The location of the DGC at costameres and the identification of its function as a link between the matrix and the cytoskeleton has led to the hypothesis that the DGC might be critical in mechanically stabilizing muscle or the sarcolemma during muscle contraction $[12,15]$.

In addition to dystroglycan and dystrophin, the core of this complex in skeletal muscle is also formed by four sarcoglycans $(\alpha, \beta, \gamma$, and $\delta)$ and sarcospan, which are thought to contribute to stabilization of the complex within the sarcolemma. Mutations in either dystrophin or the sarcoglycans are associated with reduced expression or incomplete formation of the DGC [16-18] and are hypothesized to result in muscular dystrophy through a common mechanism which includes a reduction in dystroglycan function. Therefore, reduction in the connections between the cytoskeleton and the extracellular matrix appears critical to muscular dystrophies associated with the DGC.

In addition to primary mutations in DGC components, several causative mutations have also been identified in a group of glycosyltransferases, which have been shown to function in a common pathway to glycosylate $\alpha$ dystroglycan. This O-linked glycosylation of $\alpha$-dystroglycan is essential for enabling $\alpha$-dystroglycan to function as an extracellular matrix receptor [19]. In these glycosylationdeficient muscular dystrophies, dystroglycan and the DGC are expressed and intact at the sarcolemma, but the loss of the ability of dystroglycan to bind laminin is sufficient to cause muscular dystrophy $[20,21]$. These findings highlight specifically the interaction of the DGC with extracellular matrix as a critical function of the DGC in preventing muscular dystrophy.

In the dystroglycan glycosylation-deficient mice (LARGE ${ }^{\text {myd }}$ ) electron microscopic analysis showed that the interaction of dystroglycan with laminin in the extracellular matrix appeared to tightly anchor the basal lamina to the sarcolemma [21]. This tight and regular interaction of dystroglycan with the basal lamina is proposed to protect the sarcolemma from expansion of small ruptures during mechanical activity. Mutations in dystroglycan itself appear to be quite rare in humans, perhaps related to an essential role of dystroglycan in early development [22]. Only recently has a mutation in the dystroglycan gene been identified in muscular dystrophy patients and like previous glycosyltransferase mutations, the mutation appears to impair dystroglycan glycosylation and causes loss of function without impacting dystroglycan expression [23].

The heterotrimeric protein laminin-211 is a major component of the basal lamina surrounding adult muscle fibers that is bound by glycosylated $\alpha$-dystroglycan $(\alpha$-DG). Mutations in the LAMA2 gene result in loss of laminin $\alpha 2$ expression and the most common form of congenital muscular dystrophy [24-26]. The identification of laminin $\alpha 2$ mutations only further reinforces the notion that any disruption of the connection between the muscle fiber cytoskeleton to the extracellular matrix through the DGC, whether it be reduced expression of the DGC, reduced ability of dystroglycan to interact with laminin, or loss of laminin itself from the basal lamina, is sufficient to cause muscular dystrophy.

Despite the first genetic identification of dystrophin as a causal gene in Duchenne muscular dystrophy more than two decades ago [27] and the identification of the DGC in years following [16], whether the DGC contributes purely a mechanical role in stabilizing the sarcolemma during normal contractions or imparts other significant functions in muscle still remains an area of active investigation. The identification of additional components of the DGC, such as sarcospan, dystrobrevins, and syntrophins, that do not appear to have a direct or essential role in the mechanical function of the DGC but instead appear to be docking sites for other intracellular signaling proteins [28], has fueled considerable interest in what other intracellular pathways may be affected in DGCassociated muscular dystrophies.

\section{The DGC, Sarcolemma Integrity, and Contraction-Induced Muscle Injury}

Even normal skeletal muscle is susceptible to mechanical damage, particularly during lengthening contractions, and immediate defects at the level of the sarcolemma [29], the $t$-tubules [30], or the contractile machinery [31] contribute to a transient decrease in the isometric force. Following repetitive lengthening contractions, there can also be considerable, prolonged injury and muscle dysfunction that results from muscle degeneration, swelling, and infiltration of inflammatory cells [32]. In most cases, muscle dysfunction caused by prolonged injury can be fully repaired over time by active muscle fiber regeneration from resident stem cells, known as satellite cells. This suggests that occasional sarcolemmal injuries, muscle damage, and their repair might be a critical component of the homeostasis of normal muscle.

Many of the early experiments that sought to identify the mechanism by which mutations affecting the DGC cause muscular dystrophy have utilized the $m d x$ mouse model [33]. These mice harbor a null mutation in the dystrophin gene and although they do exhibit the clinical features observed in human patients, the severity is milder [34]. A role for 
the function of dystrophin in maintaining the integrity of the sarcolemma during muscle contraction was supported by studies showing that $m d x$ muscle was highly susceptible to lengthening contraction-induced injury performed in vitro, as compared to healthy control muscle. Muscle from $m d x$ animals demonstrated an increased tendency to take up Procion orange dye from the bathing medium, which suggested an increase in sarcolemma permeability following contraction $[4,35]$. When injected into $m d x$ animals, the membrane-impermeant Evans blue dye was also selectively taken up by muscle fibers that appeared necrotic and were hypercontracted, which suggested that increased membrane permeability eventually resulted in cell death [36]. This further supported the hypothesis that muscle contractions produce membrane tears, which lead to an increase in permeability of the sarcolemma to calcium and small molecules and results in a greater degree of cell death in dystrophic muscle. Muscle from $m d x$ mice also demonstrated a measurable deficit in force generation following an in vivo lengthening contraction protocol $[37,38]$. These data support a function for dystrophin and the dystrophinglycoprotein complex, at least partially, in protecting the sarcolemma during muscle contraction and suggest that, in its absence, the sarcolemma is more susceptible to damage by contractile forces, resulting in increased permeability of ions and small molecules, and eventual cell necrosis and muscle degeneration.

Further support for a critical role of membrane integrity in muscular dystrophies was gained from a different class of muscular dystrophies associated with mutations in the dysferlin gene. Mutations in dysferlin are associated with Miyoshi myopathy and limb girdle muscular dystrophy $2 \mathrm{~B}$ in humans $[39,40]$. Dysferlin is not associated with the DGC but appears to have homology to the vesicle protein, synaptotagmin, and therefore has been predicted to be important for mediating vesicle-mediated membrane repair. While the complete functions of dysferlin are still under investigation, dysferlin has been shown to be required for rapid resealing of the sarcolemma in a calcium-dependent manner following focal membrane damage [41]. Although muscle from dysferlin-null animals is not particularly susceptible to contraction-induced damage any more so than healthy muscle [42], a recent study demonstrated that recovery of muscle following damage required an immediate and transient membrane resealing event and that dysferlindeficient muscle consequently took longer to recover [42, 43]. The identification of dysferlin as a potential mediator of membrane repair in muscle underlies the importance of sarcolemmal integrity and its maintenance by repair pathways as important mechanisms in which defects may result in muscle degeneration.

\section{Does Contraction-Induced Injury Play a Causal Role in DGC-Associated Muscular Degeneration and Dystrophy?}

While the generally accepted dogma is that mutations affecting the DGC render muscle more susceptible to contraction-induced damage during mechanical stress [44], recent evidence from our laboratory suggests that not all muscles of dystrophic animals are equally affected. We reported that, in the LARGE ${ }^{\text {myd }}$ animal model of glycosyltransferase-deficient muscular dystrophy, typical fast-twitch muscles such as the EDL were weaker than control WT EDL muscles. Additionally, LARGE ${ }^{\text {myd }}$ EDL muscles demonstrated the increased susceptibility to contractioninduced injury typical of EDL muscles of $m d x$ mice, as indicated by a dramatic loss of force following lengthening contraction that was significantly greater than controls [45]. However, a remarkably different phenotype was measured in soleus muscles, which are composed of mixtures of fast and slow fibers [45]. Although the contraction protocol resulted in a $26 \%$ force deficit in WT soleus muscle, there was no greater increase in force deficit observed in the soleus of LARGEmyd mice. Force deficits measured in WT soleus muscle were also higher than those measured in EDL muscle after two lengthening contractions, which suggested that the observed defect was not due to inherent differences in susceptibility to injury between the two muscle groups, nor to differences in dystroglycan glycosylation or laminin binding activity. However, the soleus of LARGEmyd animals was still weaker than WT muscle and dystrophic, as evidenced by an increase in degenerating fibers, accumulation of inflammatory cells, and the presence of centrally nucleated fibers. An explanation that accounts for the dystrophic features and fiber degeneration in the soleus muscle in the absence of any detectable increased susceptibility to contraction-induced injury has not been addressed.

A similar lack of increased susceptibility of muscle to contraction-induced muscle damage was previously demonstrated in the soleus of $m d x$ mice, and the authors speculated that dystrophin was not essential for maintaining structural stability in the soleus muscle [37]. Utrophin, a homologue of dystrophin, has been shown to be upregulated in the absence of dystrophin [46] and is also more highly expressed in slow-twitch fibers [47] which may therefore confer a degree of stability in the soleus muscle of $m d x$ mice that might explain this lack of susceptibility to contractioninduced injury. However, upregulation of utrophin cannot explain the results in LARGE ${ }^{\text {myd }}$ mice because, other than the loss of dystroglycan glycosylation, the DGC is assembled normally in LARGE ${ }^{\text {myd }}$ muscle $[20,21]$. We found that another important laminin receptor in muscle, $\alpha 7 \beta 1$ integrin, is expressed at much higher levels in the sarcolemma of soleus muscle as compared to other fast muscles [45]. Several reports have demonstrated that when the DGC is impaired, $\alpha 7$ or $\beta 1$ integrin is upregulated, which suggests that the two receptors may have at least some overlapping functions in muscle [48]. Susceptibility to contraction-induced injury was directly compared between $\alpha 7$ integrin-null and LARGE ${ }^{\text {myd }}$ mice using EDL muscle and only LARGE ${ }^{\text {myd }}$ muscle was shown to be more susceptible to injury [21]. This might suggest that interactions with laminin and dystroglycan are more important for mechanical stability than are the interactions between $\alpha 7 \beta 1$ integrin and laminin. However, $\alpha 7 \beta 1$ integrin expression in fast muscle is very low, and the comparison was only shown 
in fast-twitch muscle, and not in the soleus muscle, which remains to be studied. Transgenic overexpression of $\alpha 7$ integrin in dystrophin/utrophin double knockout mice can significantly improve muscle disease [49], but whether this beneficial effect is due to prevention of mechanical damage or effects on cell signaling has not been fully addressed. The potential role of integrins and the DGC in laminindependent signaling in muscle is discussed in greater detail in Section 6.

Muscle physiological studies have also been performed in an animal model of congenital muscular dystrophy, the $d y / d y$ mouse, that harbors a null mutation in the LAMA2 gene [24]. In contrast to the results demonstrated in $m d x$ mice, laminin-deficient muscle does not exhibit a defect in sarcolemmal stability [50]. Both the EDL and soleus muscles were isolated from laminin-deficient mice and subjected to a moderate lengthening contraction protocol in vitro and neither demonstrated an increased susceptibility to injury over that observed in control muscle. As a means to amplify potentially subtle defects in these mice, the anesthetic halothane was used to increase fluidity of the lipid bilayer. Although this did cause an increase in force deficit following a lengthening contraction protocol, this deficit was still not any greater in laminin-deficient muscle [50]. Because contraction protocols can vary, sarcolemmal permeability was directly compared between three different mouse models of DGC-related muscular dystrophy, $m d x$ [33] and two deficient in laminin, $d y / d y$ [24] and $d y^{2 j} / d y^{2 j}[25]$. Animals were injected intravenously with Evans blue dye and muscles were analyzed several hours after injection. Muscles from $m d x$ demonstrated an increase in dye uptake while dye uptake in laminin-deficient muscle was not different than control animals [51]. Additionally, positively stained fibers in $m d x$ mice often appeared in groups of neighboring fibers, in contrast to the few individual fibers stained in laminin-deficient muscle, which appeared necrotic. However, laminin-deficient muscle still had dystrophic pathological features, which further supports the notion that, although disruption of the sarcolemma may contribute to the pathology of muscle disease, it is not essential.

Together, these studies demonstrate that membrane damage is not required for muscle degeneration and muscular dystrophy. Although mutations that compromise DGC function can leave muscle vulnerable to membrane damage, this is not true for all muscle groups, since the soleus muscle, despite demonstrating a susceptibility to injury in healthy muscle, does not show increased susceptibility in the absence of a functional DGC. Additionally, the number of fibers that may be damaged, as evidenced by dye uptake in $m d x$ fast muscles, is not sufficient to explain the dramatic loss in force generation following injury [37]. Therefore, the DGC likely possesses other cellular functions in skeletal muscle that, when impaired, contribute to muscle degeneration and the dystrophic pathology. Potential alternative pathways and their experimental support are reviewed below.

\section{Role of the DGC in Altered Calcium Homeostasis}

Intracellular calcium is a critical mediator of several regulatory processes in skeletal muscle [52]. In dystrophic muscle, the concentration of intracellular calcium is elevated, and several potential sources for calcium entry have now been identified (Figure 1). Early studies of $m d x$ muscle demonstrated that individual fibers that showed an elevation in intracellular calcium were also necrotic, which suggested that calcium entered through membrane tears as a direct result of dystrophin loss [53, 54]. Increased intracellular calcium in $m d x$ muscle was later explained by an increase in sarcolemmal permeability attributed to calcium leak and stretched-activated channels $[55,56]$. Stretch-activated channels can be blocked in $m d x$ mice via oral delivery of streptomycin and results in a reduction in intracellular calcium and an improvement in force production [57]. In the same study, a decrease in intracellular calcium was not observed in streptomycin-treated control animals, which suggested that the activity of these channels was somehow enhanced in the absence of dystrophin.

The transient receptor potential (TRP) channels are a diverse family of ion channels composed of multiple subunits, that have also been identified as potential mediators of altered calcium homeostasis in dystrophic muscle [58]. Several TRP channels in the canonical subfamily (TRPC) are expressed in mouse skeletal muscle and TRPC1, TRPC4, and TRPC6 were initially identified as being potentially impaired in $m d x$ muscle [59]. In a later study, expression of TRPC1 was shown to be increased in $m d x$ muscle and the authors speculated that its activity may be increased due to additional upregulation of caveolin-3 and src, which contribute to the translocation of this channel to the sarcolemma [60]. Similarly, a stretch-activated TRP channel in the vanilloid receptor subfamily, TRPV2, has also been shown to be more highly expressed at the sarcolemma in $m d x$ muscle. Inhibition of TRPV2 using a dominant negative genetic approach resulted in a restoration of normal intracellular calcium levels and an amelioration of dystrophic pathology in $m d x$ mice [61].

Although the increased resting calcium concentration observed in the cytoplasm of dystrophic muscle may be the result of increased expression or activity of calcium channels at the sarcolemma, a recent study has demonstrated that an additional source of calcium entry may be due to defects at the level of the sarcoplasmic reticulum [62]. RyR1 channels isolated from $m d x$ muscle were shown to be hypernitrosylated as a potential consequence of altered nitric oxide signaling downstream of dystrophin loss. This resulted in an increased leak of calcium ions from the sarcoplasmic reticulum, and pharmacological inhibition of RyR1 was shown to reduce muscle damage in $m d x$ muscle.

While several of these studies noted an improvement in muscle health following inhibition of calcium entry in animal models of muscular dystrophy, an important study recently demonstrated that elevated calcium was sufficient to cause muscle damage in the absence of a genetic basis for muscular dystrophy [63]. The overexpression of TRPC3 


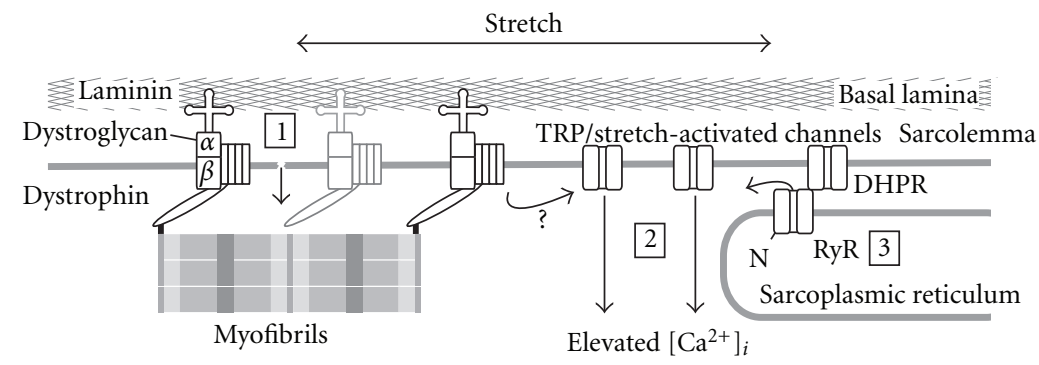

FIGURE 1: Sources of calcium entry in dystrophic muscle. (1) Disruptions to the DGC can result in instability of the sarcolemma that permits calcium entry through membrane tears when the sarcolemma is stretched during lengthening muscle contractions. (2) Activity of calcium leak, stretch-activated, and various TRP channels has been shown to be increased in dystrophin-deficient muscle and their inhibition in vivo can improve dystrophic pathology. (3) The ryanodine receptor has recently been shown to be hypernitrosylated in $m d x$ muscle which may result in an increased leak of calcium from the sarcoplasmic reticulum.

in skeletal muscle resulted in a muscle wasting phenotype with defects similar to those observed in laminin-deficient muscle. Using gene expression profiling, this phenotype was also shown to be associated with altered expression of many genes, in a pattern that was strikingly similar to gene expression changes in $\delta$-sarcoglycan deficient muscle. However, the muscle did not demonstrate any changes in expression of the DGC at the sarcolemma, which suggests that much of the muscle damage observed in DGC-related muscular dystrophies may be attributed to downstream defects in calcium homeostasis.

Elevated intracellular calcium can result in cellular damage in a number of ways that may underlie many of the defects observed in dystrophic muscle. When sustained, abnormal elevations in intracellular calcium can cause mitochondria to undergo permeability transition which can eventually lead to mitochondrially mediated apoptosis, involving swelling of the mitochondria, release of cytochrome $c$, and the activation of caspases [64]. Cyclophilin D is a mitochondrial enzyme that is important for regulating the mitochondrial permeability transition and genetic strategies have demonstrated that its absence renders mitochondria insensitive to calcium-induced cell death $[65,66]$. Both $\delta$ sarcoglycan-null and laminin-null mice have abnormally swollen mitochondria and the muscular dystrophy seen in both models can be partially alleviated by altering the pores mediating the mitochondrial permeability transition [67].

Another important downstream consequence of mitochondrial dysfunction is an increased production of reactive oxygen species (ROS), which can further exacerbate cellular damage [68]. Several studies have identified ROS as a potential mediator of muscle damage in the muscular dystrophies [69-71]. Antioxidant treatment of $m d x$ mice has demonstrated mixed results but in some cases has lessened the symptoms of muscular dystrophy [71, 72]. In a model of muscular dystrophy not associated with DGC defects but instead caused by defective collagen IV, a component of the extracellular matrix, mitochondrial dysfunction was shown to be a major source of ROS. Additionally, when ROS production was suppressed, oxidation of myofibrillar proteins was reduced and improved contractile performance [73]. Therefore, cellular mechanisms downstream of mitochondrial defects may be an important step in the process by which DGC mutations eventually result in myofiber damage and cause muscle disease.

Normal excitation-contraction coupling has been suggested to be affected by an increase in cellular calcium concentration and may also be an important contributor to muscle weakness in these diseases $[74,75]$. Elevated calcium can also directly impair muscle function by increasing the activity of calcium-dependent proteases like calpains which can cleave myofibrillar proteins [76-78]. While the genetic and pharmacological inhibition of calpains may alleviate several pathological features in $m d x$ muscle [79-81], such experiments have yielded inconsistent results and may be in part due to compensatory increases in calpain activity and/or a lack of efficacy of the proposed inhibitors [82].

Several of these studies have demonstrated that intracellular calcium is elevated in dystrophic muscle, and that this can lead to a number of deleterious effects to the cell and contribute to a decline in contractile function. More importantly, these studies have provided several alternatives by which calcium permeability and/or intracellular calcium may be increasing that are independent from direct entry of calcium through sarcolemma tears. However, it is still unclear just how distinct genetic mutations that affect the function of the DGC can alter activity of the various calcium channels that have been proposed. While inhibition of calcium entry has been shown to be beneficial in the animal models addressed, it is important to note that muscle disease was still present in these animals, albeit it to a lesser degree. This suggests that altered calcium homeostasis, whether it is through membrane tears or from altered activity of calcium channels, may not be the only mechanism downstream of genetic mutations that results in muscle damage.

\section{Laminin-Dependent Intracellular Signaling through the DGC}

Laminins exist as heterotrimeric proteins composed of specific combinations of $\alpha, \beta$, and $\gamma$ subunits and are differentially expressed in multiple cell types. Laminin-211 $(\alpha 2 / \beta 1 / \gamma 1)$ is expressed in the extracellular matrix of adult skeletal muscle and is bound with high affinity by $\alpha$-DG 
and $\alpha 7 \beta 1$ integrin. Mutations that affect $\alpha 2$ laminin, as is the case in the $d y / d y$ mouse and in congenital muscular dystrophy $1 \mathrm{~A}$, result in muscular dystrophy as a result of lost interactions with either or both laminin receptors [2426]. Although laminin is the major ligand of dystroglycan by which a connection is forged between the DGC and the extracellular matrix in skeletal muscle, laminin-211 deficient muscle is not susceptible to contraction-induced damage and does not typically show increased uptake of cell impermeant dye (reviewed in Section 4). Despite the lack of evidence for increased muscle damage, many fibers of laminin-deficient muscle are apoptotic [83], which is thought to significantly contribute to muscle disease. Both pharmacological and genetic inhibition of apoptosis (e.g., Bcl-2 overexpression, Bax inactivation) have been shown to ameliorate dystrophy in laminin- $\alpha 2$-deficient animal models [84-87]. Because there appears to be a lack of sarcolemmal damage, the mechanism by which apoptosis occurs in this disease may be independent of elevations in intracellular calcium. Alternatively, increases in apoptosis may be due to disruptions in downstream cell survival signaling as a result of lost interactions between laminin and its two major receptors in skeletal muscle.

Potential increases in survival signaling though laminin receptors in muscle could be the basis for results of a recent study that demonstrated an improvement of dystrophy in $m d x$ mice upon injection of soluble laminin-111, a laminin isoform not normally expressed in skeletal muscle [88]. While the mechanism of this effect is unclear, the benefit of laminin-111 injections may be due to either upregulation of $\alpha 7$-integrin-mediated signaling or integrinmediated stabilization of the sarcolemma [88]. However, a transgenic approach to deliver laminin-111 to skeletal muscle failed to benefit $m d x$ mice [89] despite its rescue of muscular dystrophy in laminin- $\alpha 2$-deficient muscle $[90,91]$. So while laminin $\alpha 1$ and $\alpha 2$ are normally expressed in different tissues, they appear to be functionally similar in promoting muscle cell survival. Whether this important function of laminin in muscle can be targeted therapeutically in all forms of DGCdeficient muscular dystrophy is still debatable.

Integrins are formed as heterodimers of $\alpha$ and $\beta$ subunits and the predominant alpha isoform expressed in differentiated skeletal muscle, $\alpha 7$ integrin, forms dimers with $\beta 1$ to form a laminin receptor. Mutations in $\alpha 7$ integrin result in muscular dystrophy in patients and in animal models, and a loss of $\alpha 7$ integrin in muscle has been shown to predominantly affect the structure and function of the myotendinous junction, where $\alpha 7 \beta 1$ integrin is highly expressed [92-94]. $\alpha 7 \beta 1$ integrin is also expressed at costameres and, similar to $\alpha$-dystroglycan, can associate intracellularly with cytoskeletal proteins and may contribute to mechanical stability of the sarcolemma [48]. Animals lacking both dystrophin and $\alpha 7$ integrin display a much more severe form of muscular dystrophy than animals lacking either protein alone, which suggests that both laminin receptors may be required at the sarcolemma and can potentially compensate for one another [95]. Transgenic overexpression of $\alpha 7$ integrin can partially alleviate muscle disease in dystrophin/utrophin double knock-out mice independently of any change in expression of
DGC components $[49,96]$. However, integrins are associated with a number of signaling pathways and can alter AKT and MAP kinase activity in a contraction-dependent manner [97]. Therefore, some of the improvement observed when integrins are overexpressed in dystrophic muscle may be in part due to changes in cell signaling rather than direct prevention of sarcolemma damage.

While the integrins may function as laminin-dependent signaling receptors in skeletal muscle [98], whether dystroglycan and the DGC may similarly participate in downstream signal transduction cascades is less clear. Rather than simply serving as a membrane "stabilizer", dystrophin has also been proposed to serve as a sensor for membrane tension and function early in the development of skeletal muscle [99]. The authors of this early study proposed that this function of the DGC may be achieved through either interactions with stretch-activated cation channels or through regulation of a downstream signaling mechanism analogous to integrin signaling. Such signaling would likely be important for either growth of differentiated fibers or for mediating proliferation or fusion of satellite cells with regenerating fibers. Interestingly, when the dystroglycan gene was specifically targeted in differentiated skeletal muscle using cre-loxPmediated recombination, the phenotype was surprisingly mild compared to other models of DGC-related muscular dystrophy [100]. The residual expression of dystroglycan in satellite cells suggested that dystroglycan might have an unappreciated role in this cell type, which could be important for either cell signaling within satellite cells or for interactions with the basal lamina [100]. However, how the DGC may be functioning in muscle regeneration is not known.

Given the critical role of laminin in promoting cell survival signaling in muscle and the existence of two possible receptors that might mediate its effects, dissecting the molecular mechanisms of each would certainly be a key advance towards understanding how disruptions can result in muscle disease. A truncated form of laminin- $\alpha 1$ was recently generated that lacks LG domains $4-5$ and can prevent dystroglycan binding while retaining the LG domains necessary for laminin interactions with integrins. In contrast to full length laminin- $\alpha 1$, when this truncated laminin- $\alpha 1$ was transgenically expressed in laminin- $\alpha 2$-deficient muscle, several fibers in select muscle groups were still apoptotic [101]. Because transgenic expression of full length laminin$\alpha 1$ can fully rescue the $d y / d y$ phenotype, this suggests that interactions between dystroglycan and laminin are also likely important for cell survival signaling. This is the first study to our knowledge that directly implicates dystroglycan in laminin dependent survival signaling in muscle in vivo and suggests that disruption of dystroglycan-dependent signaling may also contribute to the pathology of muscular dystrophy.

Several studies using primarily cell culture systems have shown that the DGC may be capable of participating as a scaffold for various signal transduction cascades (Figure 2). $\beta$-Dystroglycan is capable of binding multiple signaling and adaptor proteins known to be important for myoblast differentiation and cell survival signaling [102-105]. The cterminus of $\beta$-dystroglycan contains a proline-rich region 


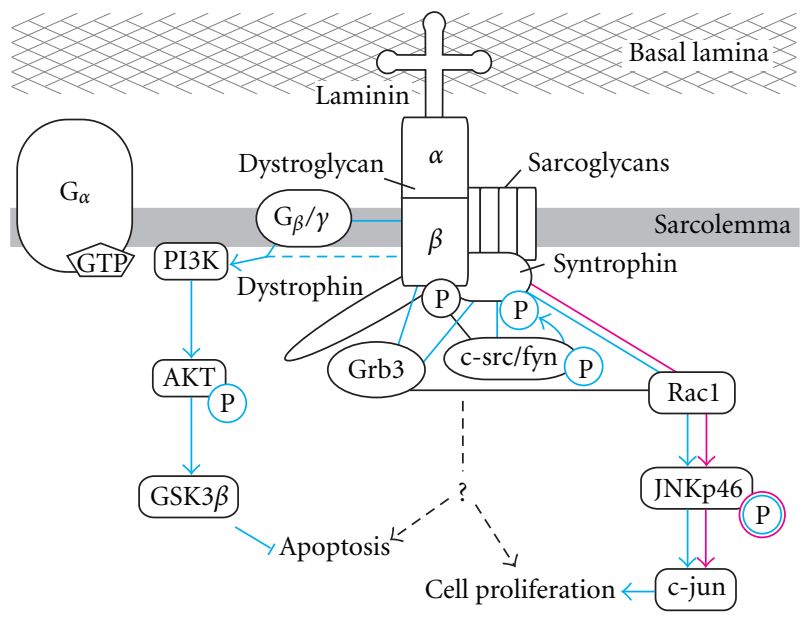

FIGURE 2: The dystrophin-glycoprotein complex may participate in laminin-dependent signaling in skeletal muscle. Interactions shown in blue indicate interactions that have been shown to be increased when laminin is bound to dystroglycan. Interactions in pink indicate those that have been shown to be increased following a muscle contraction protocol. Since the phosphorylation of $\beta$-dystroglycan can bind a number of other SH2-domain containing proteins and can also interact with Grb2, it may participate in additional signal transduction cascades that have not yet been identified. It is important to remember that in many cases, these interactions have been studied in cell culture systems and the relevance of these interactions in muscle in vivo has not been extensively studied.

that can bind Grb2, a well known adaptor protein [102, $106]$ and may be important for recruiting additional components of the MAP kinase pathway [104]. Dystroglycan can also be phosphorylated at tyrosine 892 near the cterminus of $\beta$-DG $[103,107]$ and may function to regulate interactions between dystrophin and caveolin-3 $[107,108]$. This phosphorylation has also been shown to be adhesion dependent and enables dystroglycan to recruit several SH2domain containing proteins, including c-Src and Fyn, to the sarcolemma [109]. In an unrelated study, these two kinases were also shown to be associated with the DGC and functioned to phosphorylate the DGC protein syntrophin [105]. In the presence of laminin, syntrophin was shown to associate with the DGC and mediate downstream Racl signaling that led to increased activity of c-jun. This result was suggested to explain how increased doses of laminin in vitro led to a dose-dependent increase in cell proliferation in C2C12 myoblasts [110]. An increase in Rac1 signaling was also observed following muscle contraction, which suggested that interactions between laminin and dystroglycan are important for enabling the DGC to function as a laminindependent mechanoreceptor [105].

The PI3K/AKT pathway is an important signaling pathway essential for muscle cell survival, growth, and hypertrophy that has been suspected to function downstream of the DGC. Disruption of laminin/dystroglycan binding in vitro by antibody blockade results in a decrease in PI3K-mediated phosphorylation of AKT and is associated with an increase in apoptosis [111]. This result may be mediated in part through interactions of the DGC with heterotrimeric G-proteins, which has also been shown to be laminin-dependent. In the presence of laminin, dystroglycan can be immunoprecipitated in a complex with $G \beta \gamma$ and PI3K and leads to an increase in AKT activation [112]. Therefore, the authors of this study concluded that, in muscular dystrophies where the DGC is disrupted, loss of an interaction with G $\beta \gamma$ can impair PI3K signaling and may contribute to disease pathology. Several studies have demonstrated perturbations in AKT signaling in $m d x$ muscle but generally have demonstrated an increase in AKT activity rather than a decrease that would be predicted by these cell culture studies $[112,113]$. This potentially could be due to increased AKT signaling downstream of $\alpha 7 \beta 1$ integrin, which is upregulated in $m d x$ muscle [114] and has been shown to be beneficial when overexpressed in dystrophic muscle either directly [115] or downstream of IGF-1 [116$118]$.

While the potential loss of PI3K/AKT signaling downstream of laminin binding may impact muscle function through its effect on cell survival or growth, skeletal muscle function may also be compromised due to increases in activity of the ubiquitin-proteasome system (UPS) [119]. MuRF1 and MAFbx/atrogin-1 are important mediators of skeletal muscle atrophy that function to ubiquitinate target proteins which subsequently results in their destruction by the proteasome [119]. In a recent study, decreased phosphorylation of AKT was demonstrated in laminindeficient muscle and was associated with an increase in total amount of ubiquitinated protein [120]. Additionally, pharmacological inhibition of the ubiquitin-proteasome pathway in laminin-deficient animals resulted in an amelioration of several pathological features of the disease. This led the authors to conclude that impaired laminin-dependent signaling in dystrophic muscle may also be impacting the UPS and contributing to muscle disease. Although a number of signaling pathways are known to be important for skeletal muscle growth, the exact contributions of disrupted dystroglycan-dependent or integrin-dependent signaling in dystrophic muscle still needs to be formally addressed. 


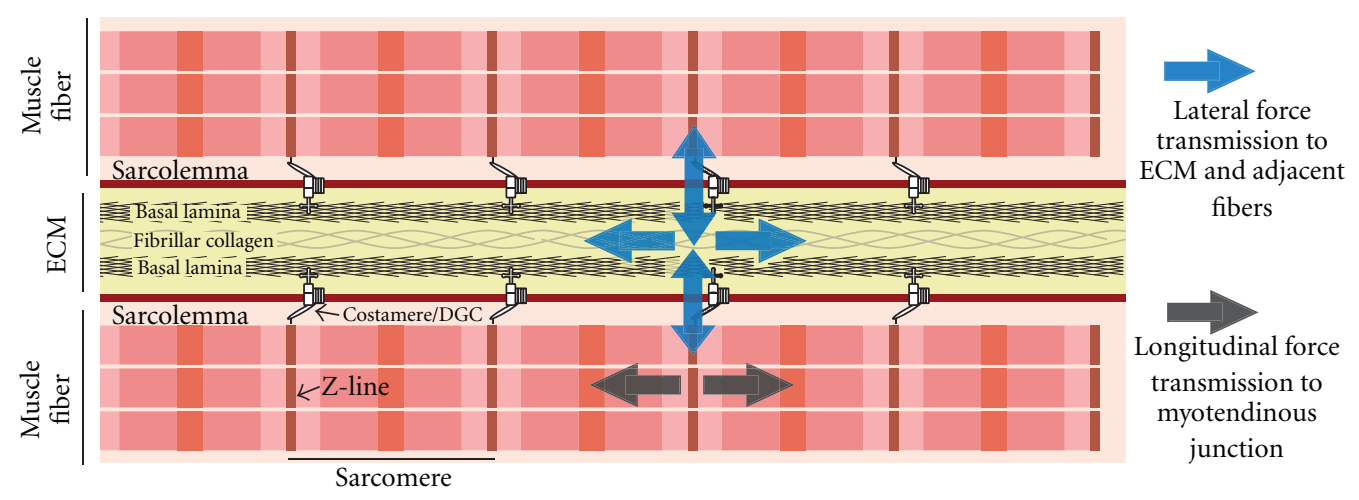

Figure 3: The dystrophin-glycoprotein complex transmits forces laterally at costameres in muscle. Longitudinal forces generated in sarcomeres are transmitted down myofibrils in muscle and forces are also transmitted laterally to the ECM and neighboring muscle fibers at costameres, at least in part through the dystrophin-glycoprotein complex (DGC). Recent data showing a loss of lateral force transmission in dystrophin-deficient muscle explains how the reduction or improper assembly of the DGC at the lateral membrane may contribute to overall muscle weakness and fragility.

\section{Direct Role of the Dystrophin-Glycoprotein Complex in Force Transmission}

While muscle damage is hypothesized to be important in the pathogenesis and progression of DGC-associated muscular dystrophy, dystrophic muscle displays considerable muscle weakness even in very early stages of the disease. This weakness, expressed as a reduction in specific force normalized to the cross sectional area of the muscle, occurs prior to muscular atrophy and can even be measured in the presence of pseudohypertrophy in early phases of the disease $[121,122]$. Our studies and the studies of others, in soleus muscle of DGC-deficient muscular dystrophies, demonstrate that the soleus muscle is also weak and this weakness is completely independent of an increased susceptibility of the muscle to damage $[38,45]$. Therefore, muscle damage that results as a consequence of contraction-induced injury cannot fully explain the muscle weakness in DGC-associated muscular dystrophy.

Given the location of the DGC at costameres in muscle, several investigators have hypothesized that the DGC might contribute to "lateral transmission of force" from the sarcomere to the lateral extracellular matrix [123-126]. While the concept of longitudinal force generated in sarcomeres and transmitted down myofibrils in muscle to the tendon is well studied, the concept of lateral force transmission is less well appreciated. This concept of lateral transmission of force in muscle was first described in frog muscle by Street in the early 1980's [127]. In these studies, force was shown to be transmitted laterally from a single dissected fiber to the fibers flanking it in a muscle fiber bundle, with little or no decrement. Formal proof that the DGC was important in lateral transmission of force in muscle was lacking. Recently, we developed a novel yoke apparatus to directly measure the transmission of force from the muscle laterally to the extracellular matrix and the epimysium [128]. Applying this approach to $m d x$ muscle, we showed for the first time that loss of DGC function in tibialis anterior muscles of $m d x$ mice was sufficient to cause an approximately
$40 \%$ loss in lateral force transmission in the muscles. While the precise contribution of each of the other components of the cytoskeleton, the costamere, and the extracellular matrix to the lateral transmission of force in muscle remains to be elucidated, the loss of lateral transmission of force may help explain how loss of the DGC at the lateral membrane contributes muscle weakness and fragility. Furthermore, the lateral transmission of force might be critical in transmitting force around the sites of focal myofiber injury in whole muscle and may help explain the markedly enhanced force deficits caused by lengthening contractions observed in fast muscles of DGC deficient animals (Figure 3).

\section{Conclusions}

Several studies have suggested that mutations affecting the DGC result in muscular dystrophy due to the importance of this complex in preserving sarcolemmal integrity. This role of the sarcolemma in muscular dystrophy is further supported by the observation that mutations that affect membrane repair can also result in muscle disease [40]. While several reports have demonstrated deficits in force production in dystrophic muscle in response to contractioninduced damage, it is not clear whether these defects are directly due to changes in sarcolemma integrity [37]. Additionally, mutations that affect the DGC have been shown to result in a muscle disease that variably affects the diaphragm, EDL, and soleus muscles. Therefore, an increased susceptibility to mechanical injury does not appear to be an essential step in the dystrophic process that leads to muscle weakness and the progressive decline in muscle function, and incidentally, cannot always account for other observed cellular disruptions such as differences in apoptosis.

An important downstream event that has been attributed to increased sarcolemma permeability through membrane tears is an increase in intracellular calcium. This rise in calcium is capable of negatively impacting skeletal muscle in a multitude of ways and may in fact be an important contributor to the pathology in these diseases. The 
mechanism by which DGC mutations can alter the activity of calcium channels is not clear but would support a hypothesis that membrane damage is not an essential event that precedes changes in calcium permeability. Although changes in calcium permeability alone can result in muscle disease, it is unlikely that this is the sole mechanism by which DGC mutations result in muscular dystrophy since interventions that have restored calcium homeostasis have not completely eliminated the disease.

Another consequence of gene mutations that have been shown to be relevant to disease pathology in muscular dystrophy are disruptions in signaling pathways that may be essential to enable skeletal muscle to adapt and respond to ongoing cycles of contraction and relaxation. Laminin mutations result in muscle disease concomitant with increases in apoptosis and a recent study suggests that this defect may be mediated in part through the DGC. In light of emerging evidence that membrane damage is not essential, this gives credence to several in vitro studies that have suggested that dystroglycan and the DGC may be participating in cell survival signaling. Therefore, dystroglycan in combination with other components in the DGC may be serving a function similar to that of $\alpha 7 \beta 1$ integrin, which has been more extensively demonstrated in mechano-related signaling $[48,49]$.

Many recent studies have demonstrated pharmacological and genetic interventions that have resulted in a dramatic improvement of the dystrophic pathology without any obvious protection of the sarcolemma from mechanical damage [129-131]. Discovery of additional signaling pathways directly downstream of the DGC, either those important for survival signaling or related to altered calcium homeostasis, may also serve as potential targets for pharmacological interventions to reduce disease pathology.

\section{Acknowledgments}

The authors would like to thank Zhyldyz Kabaeva for thoughtful discussion. J. D. Gumerson is currently supported by the University of Michigan Rackham Predoctoral Fellowship. This work was supported by NIH HL-080388 to D. E. Michele.

\section{References}

[1] G. Q. Wallace and E. M. McNally, "Mechanisms of muscle degeneration, regeneration, and repair in the muscular dystrophies," Annual Review of Physiology, vol. 71, pp. 37-57, 2009.

[2] E. M. McNally and P. Pytel, "Muscle diseases: the muscular dystrophies," Annual Review of Pathology, vol. 2, pp. 87-109, 2007.

[3] R. D. Cohn and K. P. Campbell, "Molecular basis of muscular dystrophies," Muscle and Nerve, vol. 23, no. 10, pp. 1456$1471,2000$.

[4] B. J. Petrof, J. B. Shrager, H. H. Stedman, A. M. Kelly, and H. L. Sweeney, "Dystrophin protects the sarcolemma from stresses developed during muscle contraction," Proceedings of the National Academy of Sciences of the United States of America, vol. 90, no. 8, pp. 3710-3714, 1993.
[5] B. J. Petrof, "The molecular basis of activity-induced muscle injury in Duchenne muscular dystrophy," Molecular and Cellular Biochemistry, vol. 179, no. 1-2, pp. 111-123, 1998.

[6] H. Moser, "Duchenne muscular dystrophy: pathogenetic aspects and genetic prevention," Human Genetics, vol. 66, no. 1, pp. 17-40, 1984.

[7] D. G. Allen and N. P. Whitehead, "Duchenne muscular dystrophy - what causes the increased membrane permeability in skeletal muscle?" International Journal of Biochemistry and Cell Biology, vol. 43, no. 3, pp. 290-294, 2011.

[8] C. L. Batchelor and S. J. Winder, "Sparks, signals and shock absorbers: how dystrophin loss causes muscular dystrophy," Trends in Cell Biology, vol. 16, no. 4, pp. 198-205, 2006.

[9] M. Yoshida and E. Ozawa, "Glycoprotein complex anchoring dystrophin to sarcolemma," Journal of Biochemistry, vol. 108, no. 5, pp. 748-752, 1990.

[10] K. P. Campbell and S. D. Kahl, "Association of dystrophin and an integral membrane glycoprotein," Nature, vol. 338, no. 6212 , pp. 259-262, 1989.

[11] C. Minetti, F. Beltrame, G. Marcenaro, and E. Bonilla, "Dystrophin at the plasma membrane of human muscle fibers shows a costameric localization," Neuromuscular Disorders, vol. 2, no. 2, pp. 99-109, 1992.

[12] J. M. Ervasti and K. P. Campbell, "A role for the dystrophinglycoprotein complex as a transmembrane linker between laminin and actin," Journal of Cell Biology, vol. 122, no. 4, pp. 809-823, 1993.

[13] K. P. Campbell, "Three muscular dystrophies: loss of cytoskeleton-extracellular matrix linkage," Cell, vol. 80, no. 5, pp. 675-679, 1995.

[14] M. R. Stone, A. O’Neill, D. Catino, and R. J. Bloch, “Specific interaction of the actin-binding domain of dystrophin with intermediate filaments containing keratin 19," Molecular Biology of the Cell, vol. 16, no. 9, pp. 4280-4293, 2005.

[15] I. N. Rybakova, J. R. Patel, and J. M. Ervasti, "The dystrophin complex forms a mechanically strong link between the sarcolemma and costameric actin," Journal of Cell Biology, vol. 150, no. 5, pp. 1209-1214, 2000.

[16] J. M. Ervasti and K. P. Campbell, "Membrane organization of the dystrophin-glycoprotein complex," Cell, vol. 66, no. 6, pp. 1121-1131, 1991.

[17] E. Ozawa, Y. Mizuno, Y. Hagiwara, T. Sasaoka, and M. Yoshida, "Molecular and cell biology of the sarcoglycan complex," Muscle and Nerve, vol. 32, no. 5, pp. 563-576, 2005.

[18] K. Ohlendieck and K. P. Campbell, "Dystrophin-associated proteins are greatly reduced in skeletal muscle from $\mathrm{mdx}$ mice," Journal of Cell Biology, vol. 115, no. 6, pp. 1685-1694, 1991.

[19] F. Muntoni, S. Torelli, and M. Brockington, "Muscular dystrophies due to glycosylation defects," Neurotherapeutics, vol. 5, no. 4, pp. 627-632, 2008.

[20] D. E. Michele, R. Barresi, M. Kanagawa et al., "Posttranslational disruption of dystroglycan-ligand interactions in congenital muscular dystrophies," Nature, vol. 418, no. 6896, pp. 417-422, 2002.

[21] R. Han, M. Kanagawa, T. Yoshida-Moriguchi et al., "Basal lamina strengthens cell membrane integrity via the laminin $\mathrm{G}$ domain-binding motif of $\alpha$-dystroglycan," Proceedings of the National Academy of Sciences of the United States of America, vol. 106, no. 31, pp. 12573-12579, 2009.

[22] R. A. Williamson, M. D. Henry, K. J. Daniels et al., "Dystroglycan is essential for early embryonic development: disruption of Reichert's membrane in Dag1-null mice," Human Molecular Genetics, vol. 6, no. 6, pp. 831-841, 1997. 
[23] Y. Hara, B. Balci-Hayta, T. Yoshida-Moriguchi et al., "A dystroglycan mutation associated with limb-girdle muscular dystrophy," New England Journal of Medicine, vol. 364, no. 10, pp. 939-946, 2011.

[24] H. Xu, X. R. Wu, U. M. Wewer, and E. Engvall, "Murine muscular dystrophy caused by a mutation in the laminin $\alpha 2$ (Lama2) gene," Nature Genetics, vol. 8, no. 3, pp. 297-302, 1994.

[25] Y. Sunada, S. M. Bernier, A. Utani, Y. Yamada, and K. P. Campbell, "Identification of a novel mutant transcript of laminin $\alpha 2$ chain gene responsible for muscular dystrophy and dysmyelination in dy2J mice," Human Molecular Genetics, vol. 4, no. 6, pp. 1055-1061, 1995.

[26] A. Helbling-Leclerc, X. Zhang, H. Topaloglu et al., "Mutations in the laminin $\alpha 2$-chain gene (LAMA2) cause merosindeficient congenital muscular dystrophy," Nature Genetics, vol. 11, no. 2, pp. 216-218, 1995.

[27] E. P. Hoffman, R. H. Brown Jr., and L. M. Kunkel, "Dystrophin: the protein product of the duchenne muscular dystrophy locus," Cell, vol. 51, no. 6, pp. 919-928, 1987.

[28] T. Haenggi and J. M. Fritschy, "Role of dystrophin and utrophin for assembly and function of the dystrophin glycoprotein complex in non-muscle tissue," Cellular and Molecular Life Sciences, vol. 63, no. 14, pp. 1614-1631, 2006.

[29] P. L. McNeil and R. Khakee, "Disruptions of muscle fiber plasma membranes: role in exercise-induced damage," American Journal of Pathology, vol. 140, no. 5, pp. 1097-1109, 1992.

[30] C. P. Ingalls, G. L. Warren, J. H. Williams, C. W. Ward, and R. B. Armstrong, "E-C coupling failure in mouse EDL muscle after in vivo eccentric contractions," Journal of Applied Physiology, vol. 85, no. 1, pp. 58-67, 1998.

[31] D. J. Newham, G. McPhail, K. R. Mills, and R. H. T. Edwards, "Ultrastructural changes after concentric and eccentric contractions of human muscle," Journal of the Neurological Sciences, vol. 61, no. 1, pp. 109-122, 1983.

[32] P. M. Clarkson and M. J. Hubal, "Exercise-induced muscle damage in humans," American Journal of Physical Medicine and Rehabilitation, vol. 81, supplement 11, pp. S52-S69, 2002.

[33] G. Bulfield, W. G. Siller, P. A. L. Wight, and K. J. Moore, "X chromosome-linked muscular dystrophy ( $\mathrm{mdx}$ ) in the mouse," Proceedings of the National Academy of Sciences of the United States of America, vol. 81, no. 4, pp. 1189-1192, 1984.

[34] C. Pastoret and A. Sebille, "mdx mice show progressive weakness and muscle deterioration with age," Journal of the Neurological Sciences, vol. 129, no. 2, pp. 97-105, 1995.

[35] P. Moens, P. H. Baatsen, and G. Marechal, "Increased susceptibility of EDL muscles from mdx mice to damage induced by contractions with stretch," Journal of Muscle Research and Cell Motility, vol. 14, no. 4, pp. 446-451, 1993.

[36] R. Matsuda, A. Nishikawa, and H. Tanaka, "Visualization of dystrophic muscle fibers in Mdx mouse by vital staining with Evans blue: evidence of apoptosis in dystrophin-deficient muscle," Journal of Biochemistry, vol. 118, no. 5, pp. 959-964, 1995.

[37] C. M. Consolino and S. V. Brooks, "Susceptibility to sarcomere injury induced by single stretches of maximally activated muscles of mdx mice," Journal of Applied Physiology, vol. 96, no. 2, pp. 633-638, 2004.

[38] C. Dellorusso, R. W. Crawford, J. S. Chamberlain, and S. V. Brooks, "Tibialis anterior muscles in mdx mice are highly susceptible to contraction-induced injury," Journal of Muscle Research and Cell Motility, vol. 22, no. 5, pp. 467-475, 2001.
[39] R. Bashir, S. Britton, T. Strachan et al., "A gene related to Caenorhabditis elegans spermatogenesis factor fer- 1 is mutated in limb-girdle muscular dystrophy type 2B," Nature Genetics, vol. 20, no. 1, pp. 37-42, 1998.

[40] J. Liu, M. Aoki, I. Illa et al., "Dysferlin, a novel skeletal muscle gene, is mutated in Miyoshi myopathy and limb girdle muscular dystrophy," Nature Genetics, vol. 20, no. 1, pp. 3136, 1998.

[41] D. Bansal, K. Miyake, S. S. Vogel et al., "Defective membrane repair in dysferlin-deficient muscular dystrophy," Nature, vol. 423, no. 6936, pp. 168-172, 2003.

[42] J. A. Roche, R. M. Lovering, and R. J. Bloch, "Impaired recovery of dysferlin-null skeletal muscle after contractioninduced injury in vivo," NeuroReport, vol. 19, no. 16, pp. 1579-1584, 2008.

[43] J. A. Roche, R. M. Lovering, R. Roche, L. W. Ru, P. W. Reed, and R. J. Bloch, "Extensive mononuclear infiltration and myogenesis characterize recovery of dysferlin-null skeletal muscle from contraction-induced injuries," American Journal of Physiology, vol. 298, no. 2, pp. C298-C312, 2010.

[44] K. E. Davies and K. J. Nowak, "Molecular mechanisms of muscular dystrophies: old and new players," Nature Reviews Molecular Cell Biology, vol. 7, no. 10, pp. 762-773, 2006.

[45] J. D. Gumerson, Z. T. Kabaeva, C. S. Davis, J. A. Faulkner, and D. E. Michele, "Soleus muscle in glycosylation-deficient muscular dystrophy is protected from contraction-induced injury," American Journal of Physiology, vol. 299, no. 6, pp. C1430-C1440, 2010.

[46] H. Tanaka, T. Ishiguro, C. Eguchi, K. Saito, and E. Ozawa, "Expression of a dystrophin-related protein associated with the skeletal muscle cell membrane," Histochemistry, vol. 96, no. 1, pp. 1-5, 1991.

[47] A. O. Gramolini, G. Bélanger, J. M. Thompson, J. V. Chakkalakal, and B. J. Jasmin, "Increased expression of utrophin in a slow vs. a fast muscle involves posttranscriptional events," American Journal of Physiology, vol. 281, no. 4, pp. C1300-C1309, 2001.

[48] B. L. Hodges, Y. K. Hayashi, I. Nonaka, W. Wang, K. Arahata, and S. J. Kaufman, "Altered expression of the $\alpha 7 \beta 1$ integrin in human and murine muscular dystrophies," Journal of Cell Science, vol. 110, no. 22, pp. 2873-2881, 1997.

[49] D. J. Burkin, G. Q. Wallace, K. J. Nicol, D. J. Kaufman, and S. J. Kaufman, "Enhanced expression of the $\alpha 7 \beta 1$ integrin reduces muscular dystrophy and restores viability in dystrophic mice," Journal of Cell Biology, vol. 152, no. 6, pp. 1207-1218, 2001.

[50] S. I. Head, A. J. Bakker, and G. Liangas, "EDL and soleus muscles of the C57BL6J/dy2j laminin- $\alpha$ 2-deficient dystrophic mouse are not vulnerable to eccentric contractions," Experimental Physiology, vol. 89, no. 5, pp. 531-539, 2004.

[51] V. Straub, J. A. Rafael, J. S. Chamberlain, and K. P. Campbell, "Animal models for muscular dystrophy show different patterns of sarcolemmal disruption," Journal of Cell Biology, vol. 139, no. 2, pp. 375-385, 1997.

[52] E. R. Chin, "Intracellular $\mathrm{Ca}^{2+}$ signaling in skeletal muscle: decoding a complex message," Exercise and Sport Sciences Reviews, vol. 38, no. 2, pp. 76-85, 2010.

[53] P. R. Turner, T. Westwood, C. M. Regen, and R. A. Steinhardt, "Increased protein degradation results from elevated free calcium levels found in muscle from mdx mice," Nature, vol. 335, no. 6192, pp. 735-738, 1988.

[54] B. A. Valentine, B. J. Cooper, and E. A. Gallagher, "Intracellular calcium in canine muscle biopsies," Journal of Comparative Pathology, vol. 100, no. 3, pp. 223-230, 1989. 
[55] A. Franco Jr. and J. B. Lansman, "Calcium entry through stretch-inactivated ion channels in mdx myotubes," Nature, vol. 344, no. 6267, pp. 670-673, 1990.

[56] P. Y. Fong, P. R. Turner, W. F. Denetclaw, and R. A. Steinhardt, "Increased activity of calcium leak channels in myotubes of Duchenne human and mdx mouse origin," Science, vol. 250, no. 4981, pp. 673-676, 1990.

[57] E. W. Yeung, N. P. Whitehead, T. M. Suchyna, P. A. Gottlieb, F. Sachs, and D. G. Allen, "Effects of stretch-activated channel blockers on $\left[\mathrm{Ca}^{2+}\right] \mathrm{i}$ and muscle damage in the mdx mouse," Journal of Physiology, vol. 562, no. 2, pp. 367-380, 2005.

[58] D. E. Clapham, "TRP channels as cellular sensors," Nature, vol. 426, no. 6966, pp. 517-524, 2003.

[59] C. Vandebrouck, D. Martin, M. C. V. Schoor, H. Debaix, and P. Gailly, "Involvement of TRPC in the abnormal calcium influx observed in dystrophic $(\mathrm{mdx})$ mouse skeletal muscle fibers," Journal of Cell Biology, vol. 158, no. 6, pp. 1089-1096, 2002.

[60] O. L. Gervasio, N. R. Whitehead, E. W. Yeung, W. D. Phillips, and D. G. Allen, "TRPC1 binds to caveolin-3 and is regulated by Src kinase-role in Duchenne muscular dystrophy," Journal of Cell Science, vol. 121, no. 13, pp. 22462255, 2008.

[61] Y. Iwata, Y. Katanosaka, Y. Arai, M. Shigekawa, and S. Wakabayashi, "Dominant-negative inhibition of $\mathrm{Ca}^{2+}$ influx via TRPV2 ameliorates muscular dystrophy in animal models," Human Molecular Genetics, vol. 18, no. 5, pp. 824-834, 2009.

[62] A. M. Bellinger, S. Reiken, C. Carlson et al., "Hypernitrosylated ryanodine receptor calcium release channels are leaky in dystrophic muscle," Nature Medicine, vol. 15, no. 3, pp. 325-330, 2009.

[63] D. P. Millay, S. A. Goonasekera, M. A. Sargent, M. Maillet, B. J. Aronow, and J. D. Molkentin, "Calcium influx is sufficient to induce muscular dystrophy through a TRPC-dependent mechanism," Proceedings of the National Academy of Sciences of the United States of America, vol. 106, no. 45, pp. 1902319028, 2009.

[64] S. Orrenius, B. Zhivotovsky, and P. Nicotera, "Regulation of cell death: the calcium-apoptosis link," Nature Reviews Molecular Cell Biology, vol. 4, no. 7, pp. 552-565, 2003.

[65] C. P. Baines, R. A. Kaiser, N. H. Purcell et al., "Loss of cyclophilin D reveals a critical role for mitochondrial permeability transition in cell death," Nature, vol. 434, no. 7033, pp. 658-662, 2005.

[66] T. Nakagawa, S. Shimizu, T. Watanabe et al., "Cyclophilin Ddependent mitochondrial permeability transition regulates some necrotic but not apoptotic cell death," Nature, vol. 434, no. 7033, pp. 652-658, 2005.

[67] D. P. Millay, M. A. Sargent, H. Osinska et al., "Genetic and pharmacologic inhibition of mitochondrial-dependent necrosis attenuates muscular dystrophy," Nature Medicine, vol. 14, no. 4, pp. 442-447, 2008.

[68] V. M. Shkryl, A. S. Martins, N. D. Ullrich, M. C. Nowycky, E. Niggli, and N. Shirokova, "Reciprocal amplification of ROS and $\mathrm{Ca}^{2+}$ signals in stressed mdx dystrophic skeletal muscle fibers," Pflugers Archiv European Journal of Physiology, vol. 458, no. 5, pp. 915-928, 2009.

[69] T. A. Rando, "Oxidative stress and the pathogenesis of muscular dystrophies," American Journal of Physical Medicine and Rehabilitation, vol. 81, supplement 11, pp. S175-S186, 2002.

[70] N. P. Whitehead, E. W. Yeung, and D. G. Allen, "Muscle damage in $\mathrm{mdx}$ (dystrophic) mice: role of calcium and reactive oxygen species," Clinical and Experimental Pharmacology and Physiology, vol. 33, no. 7, pp. 657-662, 2006.
[71] J. G. Tidball and M. Wehling-Henricks, "The role of free radicals in the pathophysiology of muscular dystrophy," Journal of Applied Physiology, vol. 102, no. 4, pp. 1677-1686, 2007.

[72] T. M. Buetler, M. Renard, E. A. Offord, H. Schneider, and U. T. Ruegg, "Green tea extract decreases muscle necrosis in mdx mice and protects against reactive oxygen species," American Journal of Clinical Nutrition, vol. 75, no. 4, pp. 749753, 2002.

[73] S. Menazza, B. Blaauw, T. Tiepolo et al., "Oxidative stress by monoamine oxidases is causally involved in myofiber damage in muscular dystrophy," Human Molecular Genetics, vol. 19, no. 21, pp. 4207-4215, 2010.

[74] R. M. Lovering, L. Michaelson, and C. W. Ward, "Malformed mdx myofibers have normal cytoskeletal architecture yet altered EC coupling and stress-induced $\mathrm{Ca}^{2+}$ signaling," American Journal of Physiology, vol. 297, no. 3, pp. C571C580, 2009.

[75] C. E. Woods, D. Novo, M. DiFranco, and J. L. Vergara, "The action potential-evoked sarcoplasmic reticulum calcium release is impaired in $\mathrm{mdx}$ mouse muscle fibres," Journal of Physiology, vol. 557, no. 1, pp. 59-75, 2004.

[76] B. T. Zhang, S. S. Yeung, D. G. Allen, L. Qin, and E. W. Yeung, "Role of the calcium-calpain pathway in cytoskeletal damage after eccentric contractions," Journal of Applied Physiology, vol. 105, no. 1, pp. 352-357, 2008.

[77] M. J. Spencer, D. E. Croall, and J. G. Tidball, "Calpains are activated in necrotic fibers from $\mathrm{mdx}$ dystrophic mice," Journal of Biological Chemistry, vol. 270, no. 18, pp. 1090910914, 1995.

[78] J. M. Alderton and R. A. Steinhardt, "Calcium influx through calcium leak channels is responsible for the elevated levels of calcium-dependent proteolysis in dystrophic myotubes," Journal of Biological Chemistry, vol. 275, no. 13, pp. 94529460, 2000.

[79] M. J. Spencer and R. L. Mellgren, "Overexpression of a calpastatin transgene in $\mathrm{mdx}$ muscle reduces dystrophic pathology," Human Molecular Genetics, vol. 11, no. 21, pp. 2645-2655, 2002.

[80] A. Briguet, M. Erb, I. Courdier-Fruh et al., "Effect of calpain and proteasome inhibition on $\mathrm{Ca}_{2+}$-dependent proteolysis and muscle histopathology in the mdx mouse," FASEB Journal, vol. 22, no. 12, pp. 4190-4200, 2008.

[81] M. A. Badalamente and A. Stracher, "Delay of muscle degeneration and necrosis in $\mathrm{mdx}$ mice by calpain inhibition," Muscle and Nerve, vol. 23, no. 1, pp. 106-111, 2000.

[82] J. Selsby, K. Pendrak, M. Zadel et al., "Leupeptin-based inhibitors do not improve the mdx phenotype," American Journal of Physiology, vol. 299, no. 5, pp. R1192-R1201, 2010.

[83] T. Mukasa, T. Momoi, and M. Y. Momoi, "Activation of caspase-3 apoptotic pathways in skeletal muscle fibers in laminin alpha 2-deficient mice," Biochemical and Biophysical Research Communications, vol. 260, no. 1, pp. 139-142, 1999.

[84] M. Erb, S. Meinen, P. Barzaghi et al., "Omigapil ameliorates the pathology of muscle dystrophy caused by laminin$\alpha 2$ deficiency," Journal of Pharmacology and Experimental Therapeutics, vol. 331, no. 3, pp. 787-795, 2009.

[85] M. Girgenrath, M. L. Beermann, V. K. Vishnudas, S. Homma, and J. B. Miller, "Pathology is alleviated by doxycycline in a laminin- $\alpha 2$-null model of congenital muscular dystrophy," Annals of Neurology, vol. 65, no. 1, pp. 47-56, 2009.

[86] M. Girgenrath, J. A. Dominov, C. A. Kostek, and J. B. Miller, "Inhibition of apoptosis improves outcome in a model of congenital muscular dystrophy," Journal of Clinical Investigation, vol. 114, no. 11, pp. 1635-1639, 2004. 
[87] P. H. Vachon, H. Xu, L. Liu et al., "Integrins $(\alpha 7 \beta 1)$ in muscle function and survival disrupted expression in merosindeficient congenital muscular dystrophy," Journal of Clinical Investigation, vol. 100, no. 7, pp. 1870-1881, 1997.

[88] J. E. Rooney, P. B. Gurpur, and D. J. Burkin, "Laminin-111 protein therapy prevents muscle disease in the mdx mouse model for Duchenne muscular dystrophy," Proceedings of the National Academy of Sciences of the United States of America, vol. 106, no. 19, pp. 7991-7996, 2009.

[89] K. I. Gawlik, B. M. Oliveira, and M. Durbeej, “Transgenic expression of laminin alpha 1 chain does not prevent muscle disease in the mdx mouse model for Duchenne muscular dystrophy," American Journal of Pathology, vol. 178, no. 4, pp. 1728-1737, 2011.

[90] K. Gawlik, Y. Miyagoe-Suzuki, P. Ekblom, S. Takeda, and M. Durbeej, "Laminin $\alpha 1$ chain reduces muscular dystrophy in laminin chain deficient mice," Human Molecular Genetics, vol. 13, no. 16, pp. 1775-1784, 2004.

[91] K. I. Gawlik and M. Durbeej, "Transgenic overexpression of laminin $\alpha 1$ chain in laminin $\alpha 2$ chain-deficient mice rescues the disease throughout the lifespan," Muscle and Nerve, vol. 42, no. 1, pp. 30-37, 2010.

[92] Y. K. Hayashi, F. L. Chou, E. Engvall et al., "Mutations in the integrin $\alpha 7$ gene cause congenital myopathy," Nature Genetics, vol. 19, no. 1, pp. 94-97, 1998.

[93] U. Mayer, G. Saher, R. Fässler et al., "Absence of integrin $\alpha 7$ causes a novel form of muscular dystrophy," Nature Genetics, vol. 17, no. 3, pp. 318-323, 1997.

[94] H. Nakashima, T. Kibe, and K. Yokochi, "'Congenital muscular dystrophy caused by integrin $\alpha 7$ deficiency", Developmental Medicine and Child Neurology, vol. 51, no. 3, p. 245, 2009.

[95] J. E. Rooney, J. V. Welser, M. A. Dechert, N. L. Flintoff-Dye, S. J. Kaufman, and D. J. Burkin, "Severe muscular dystrophy in mice that lack dystrophin and $\alpha 7$ integrin," Journal of Cell Science, vol. 119, no. 11, pp. 2185-2195, 2006.

[96] D. J. Burkin, G. Q. Wallace, D. J. Milner, E. J. Chaney, J. A. Mulligan, and S. J. Kaufman, "Transgenic expression of $\alpha 7 \beta 1$ integrin maintains muscle integrity, increases regenerative capacity, promotes hypertrophy, and reduces cardiomyopathy in dystrophic mice," American Journal of Pathology, vol. 166, no. 1, pp. 253-263, 2005.

[97] M. D. Boppart, D. J. Burkin, and S. J. Kaufman, “ $\alpha 7 \beta 1$ Integrin regulates mechanotransduction and prevents skeletal muscle injury," American Journal of Physiology, vol. 290, no. 6, pp. C1660-C1665, 2006.

[98] M. A. Schwartz, "Integrins and extracellular matrix in mechanotransduction," Cold Spring Harbor Perspectives in Biology, vol. 2, no. 12, p. a005066, 2010.

[99] S. C. Brown and J. A. Lucy, "Dystrophin as a mechanochemical transducer in skeletal muscle," BioEssays, vol. 15, no. 6, pp. 413-419, 1993.

[100] R. D. Cohn, M. D. Henry, D. E. Michele et al., "Disruption of Dag1 in differentiated skeletal muscle reveals a role for dystroglycan in muscle regeneration," Cell, vol. 110, no. 5, pp. 639-648, 2002.

[101] K. I. Gawlik, M. Åkerlund, V. Carmignac, H. Elamaa, and M. Durbeej, "Distinct roles for laminin globular domains in laminin $\alpha 1$ chain mediated rescue of murine laminin alpha 2 chain deficiency," PLoS One, vol. 5, no. 7, Article ID e11549, 2010.

[102] B. Yang, D. Jung, D. Motto, J. Meyer, G. Koretzky, and K. P. Campbell, "SH3 domain-mediated interaction of dystroglycan and Grb2," Journal of Biological Chemistry, vol. 270, no. 20, pp. 11711-11714, 1995.

[103] M. James, A. Nuttall, J. L. Ilsley et al., "Adhesion-dependent tyrosine phosphorylation of $\beta$-dystroglycan regulates its interaction with utrophin," Journal of Cell Science, vol. 113, no. 10, pp. 1717-1726, 2000.

[104] H. J. Spence, A. S. Dhillon, M. James, and S. J. Winder, "Dystroglycan, a scaffold for the ERK-MAP kinase cascade," EMBO Reports, vol. 5, no. 5, pp. 484-489, 2004.

[105] Y. Zhou, D. Jiang, D. B. Thomason, and H. W. Jarrett, "Laminin-induced activation of Rac1 and JNKp46 is initiated by Src family kinases and mimics the effects of skeletal muscle contraction," Biochemistry, vol. 46, no. 51, pp. 14907-14916, 2007.

[106] K. Russo, E. Di Stasio, G. Macchia, and G. Rosa, "Characterization of the beta-dystroglycan-growth factor receptor 2 (Grb2) interaction," Biochemical and Biophysical Research Communications, vol. 274, no. 1, pp. 93-98, 2000.

[107] J. L. Ilsley, M. Sudol, and S. J. Winder, "The interaction of dystrophin with $\beta$-dystroglycan is regulated by tyrosine phosphorylation," Cellular Signalling, vol. 13, no. 9, pp. 625632, 2001.

[108] J. L. Ilsley, M. Sudol, and S. J. Winder, "The WW domain: linking cell signalling to the membrane cytoskeleton," Cellular Signalling, vol. 14, no. 3, pp. 183-189, 2002.

[109] F. Sotgia, H. Lee, M. T. Bedford, T. Petrucci, M. Sudol, and M. P. Lisanti, "Tyrosine phosphorylation of $\beta$-dystroglycan at its WW domain binding motif, $\mathrm{PPxY}$, recruits $\mathrm{SH} 2$ domain containing proteins," Biochemistry, vol. 40, no. 48, pp. 1458514592, 2001.

[110] S. A. Oak, Y. W. Zhou, and H. W. Jarrett, "Skeletal muscle signaling pathway through the dystrophin glycoprotein complex and Rac1," Journal of Biological Chemistry, vol. 278, no. 41, pp. 39287-39295, 2003.

[111] K. J. Langenbach and T. A. Rando, "Inhibition of dystroglycan binding to laminin disrupts the PI3K/AKT pathway and survival signaling in muscle cells," Muscle and Nerve, vol. 26, no. 5, pp. 644-653, 2002.

[112] Y. Xiong, Y. Zhou, and H. W. Jarrett, "Dystrophin glycoprotein complex-associated G $\beta \gamma$ subunits activate phosphatidylinositol-3-kinase/akt signaling in skeletal muscle in a laminin-dependent manner," Journal of Cellular Physiology, vol. 219, no. 2, pp. 402-414, 2009.

[113] C. Dogra, H. Changotra, J. E. Wergedal, and A. Kumar, "Regulation of phosphatidylinositol 3-kinase (PI3K)/Akt and nuclear factor-kappa B signaling pathways in dystrophindeficient skeletal muscle in response to mechanical stretch," Journal of Cellular Physiology, vol. 208, no. 3, pp. 575-585, 2006.

[114] M. D. Boppart, D. J. Burkin, and S. J. Kaufman, "Activation of AKT signaling promotes cell growth and survival in $\alpha 7 \beta 1$ integrin-mediated alleviation of muscular dystrophy," Biochimica et Biophysica Acta, vol. 1812, no. 4, pp. 439-446, 2011.

[115] B. Blaauw, C. Mammucari, L. Toniolo et al., "Akt activation prevents the force drop induced by eccentric contractions in dystrophin-deficient skeletal muscle," Human Molecular Genetics, vol. 17, no. 23, pp. 3686-3696, 2008.

[116] A. Kumar, J. Yamauchi, T. Girgenrath, and M. Girgenrath, "Muscle-specific expression of insulin-like growth factor 1 improves outcome in Lama2 ${ }^{D y-w}$ mice, a model for congenital muscular dystrophy type 1A," Human Molecular Genetics, vol. 20, no. 12, pp. 2333-2343, 2011. 
[117] E. R. Barton, L. Morris, A. Musaro, N. Rosenthal, and H. Lee Sweeney, "Muscle-specific expression of insulin-like growth factor I counters muscle decline in mdx mice," Journal of Cell Biology, vol. 157, no. 1, pp. 137-147, 2002.

[118] T. Shavlakadze, J. White, J. F. Hoh, N. Rosenthal, and M. D. Grounds, "Targeted expression of insulin-like growth factorI reduces early myofiber necrosis in dystrophic mdx mice," Molecular Therapy, vol. 10, no. 5, pp. 829-843, 2004.

[119] D. J. Glass, "Signalling pathways that mediate skeletal muscle hypertrophy and atrophy," Nature Cell Biology, vol. 5, no. 2, pp. 87-90, 2003.

[120] V. Carmignac, R. Quere, and M. Durbeej, "Proteasome inhibition improves the muscle of laminin $\alpha 2$ chain-deficient mice," Human Molecular Genetics, vol. 20, no. 3, pp. 541-552, 2011.

[121] R. W. Grange, T. G. Gainer, K. M. Marschner, R. J. Talmadge, and J. T. Stull, "Fast-twitch skeletal muscles of dystrophic mouse pups are resistant to injury from acute mechanical stress," American Journal of Physiology, vol. 283, no. 4, pp. C1090-C1101, 2002.

[122] D. A. Lowe, B. O. Williams, D. D. Thomas, and R. W. Grange, "Molecular and cellular contractile dysfunction of dystrophic muscle from young mice," Muscle and Nerve, vol. 34, no. 1, pp. 92-100, 2006.

[123] R. J. Bloch, P. Reed, A. O’Neill et al., “Costameres mediate force transduction in healthy skeletal muscle and are altered in muscular dystrophies," Journal of Muscle Research and Cell Motility, vol. 25, no. 8, pp. 590-592, 2004.

[124] J. M. Ervasti, “Costameres: the Achilles' heel of Herculean muscle," Journal of Biological Chemistry, vol. 278, no. 16, pp. 13591-13594, 2003.

[125] R. J. Bloch and H. Gonzalez-Serratos, "Lateral force transmission across costameres in skeletal muscle," Exercise and Sport Sciences Reviews, vol. 31, no. 2, pp. 73-78, 2003.

[126] A. C. Paul, P. W. Sheard, S. J. Kaufman, and M. J. Duxson, "Localization of $\alpha 7$ integrins and dystrophin suggests potential for both lateral and longitudinal transmission of tension in large mammalian muscles," Cell and Tissue Research, vol. 308, no. 2, pp. 255-265, 2002.

[127] S. F. Street, "Lateral transmission of tension in frog myofibers: a myofibrillar network and transverse cytoskeletal connections are possible transmitters," Journal of Cellular Physiology, vol. 114, no. 3, pp. 346-364, 1983.

[128] K. S. Ramaswamy, M. L. Palmer, J. H. van der Meulen et al., "Lateral transmission of force is impaired in skeletal muscles of dystrophic mice and very old rats," Journal of Physiology, vol. 589, no. 5, pp. 1195-1208, 2011.

[129] C. M. Adamo, D. F. Dai, J. M. Percival et al., "Sildenafil reverses cardiac dysfunction in the mdx mouse model of Duchenne muscular dystrophy," Proceedings of the National Academy of Sciences of the United States of America, vol. 107, no. 44, pp. 19079-19083, 2010.

[130] N. P. Evans, J. A. Call, J. Bassaganya-Riera, J. L. Robertson, and R. W. Grange, "Green tea extract decreases muscle pathology and NF- $\kappa$ B immunostaining in regenerating muscle fibers of mdx mice," Clinical Nutrition, vol. 29, no. 3, pp. 391-398, 2010.

[131] N. P. Whitehead, C. Pham, O. L. Gervasio, and D. G. Allen, "N-Acetylcysteine ameliorates skeletal muscle pathophysiology in mdx mice," Journal of Physiology, vol. 586, no. 7, pp. 2003-2014, 2008. 

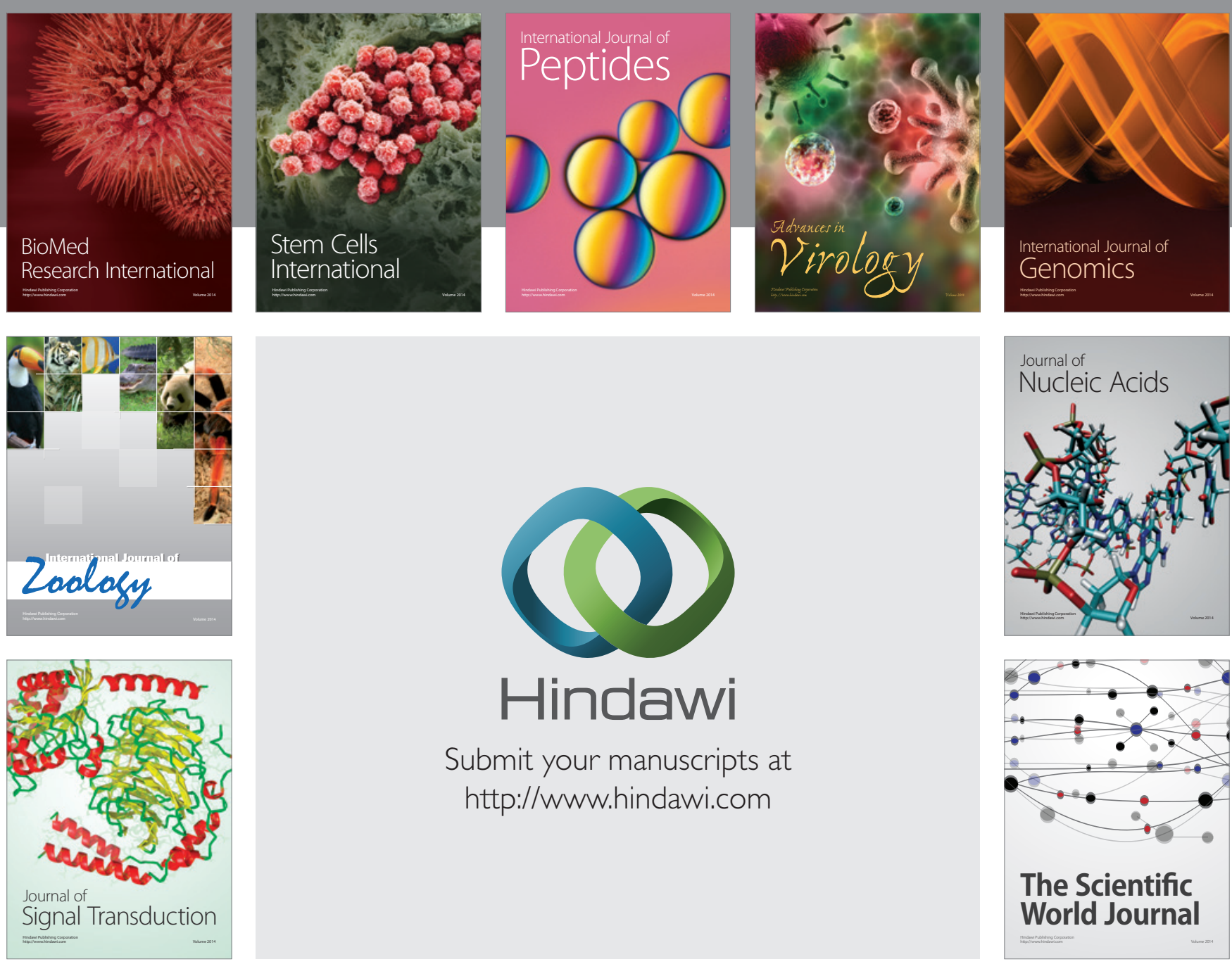

Submit your manuscripts at

http://www.hindawi.com
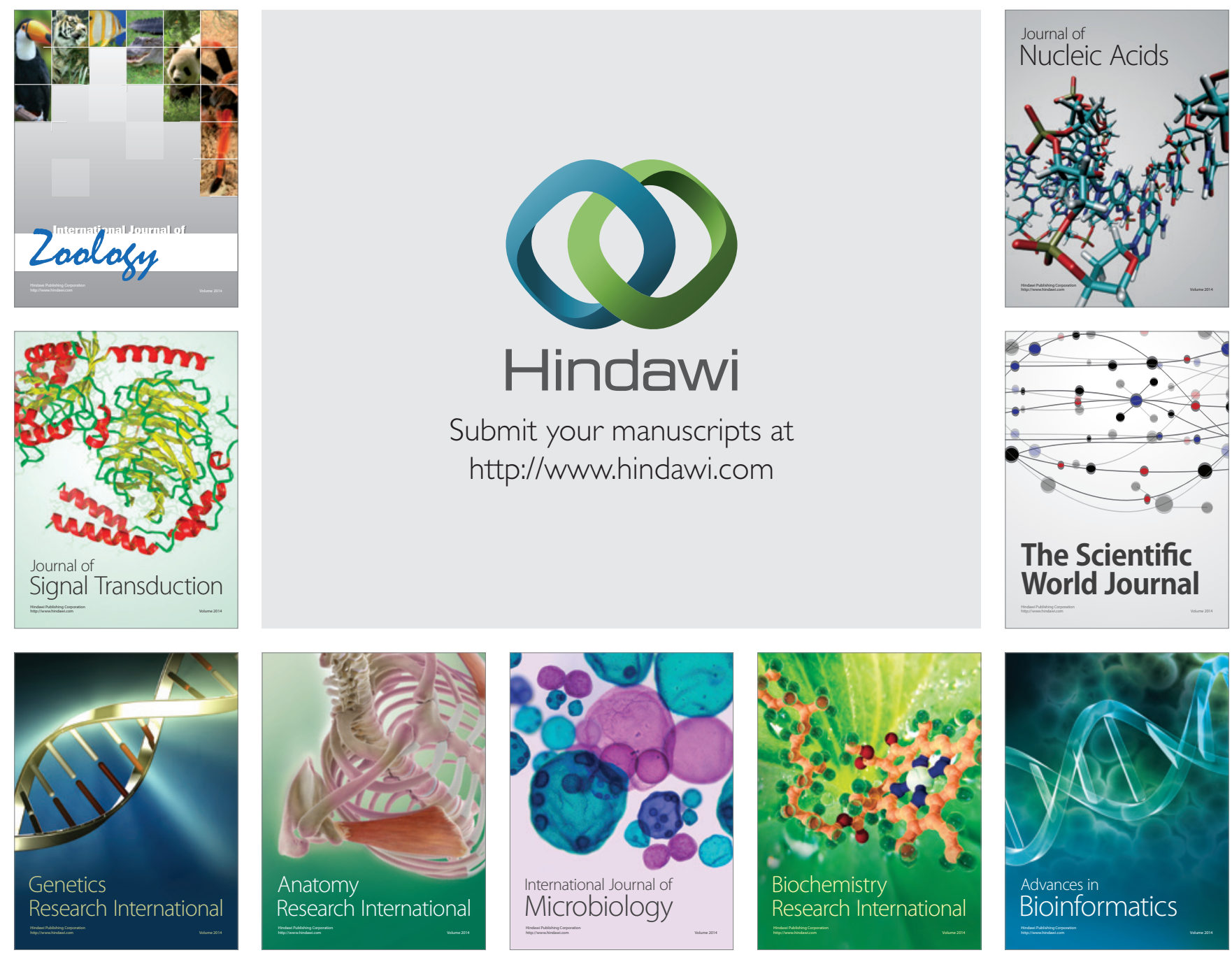

The Scientific World Journal
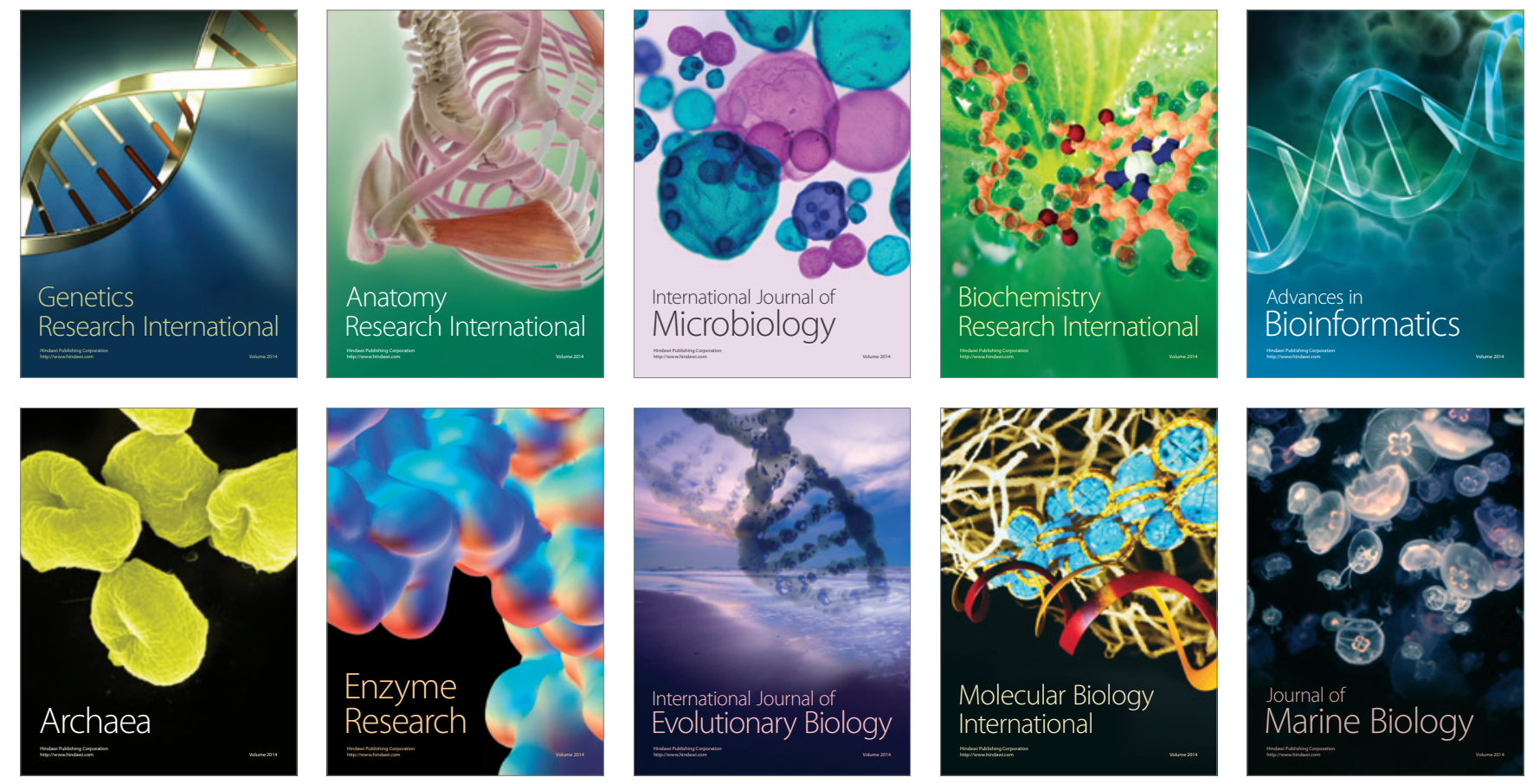